\section{Revista de \\ Economid \\ Contemporâned

Revista de Economia Contemporânea (2014) 18(2): p. 317-324

(Journal of Contemporary Economics)

ISSN (Versão Impressa) 1415-9848

http://dx.doi.org/10.1590/141598481827

www.ie.ufrj.br/revista

www.scielo.br/rec

\title{
SISTEMA FINANCEIRO, BANCOS E FINANCIAMENTO DA ECONOMIA: UMA ABORDAGEM KEYNESIANA
}

\author{
Douglas Alcantara Alencar ${ }^{\text {a }}$ \\ aprofessor-assistente licenciado das Faculdades Metropolitanas Unidas (FMU)
}

Resenha recebida em 21/01/2014 e aceita em 30/09/2014

Resenha do livro: PAULA, L. F. Sistema Financeiro, bancos e financiamento da economia: uma abordagem keynesiana. Rio de Janeiro: Campus/Elsevier, 2014.

\section{INTRODUÇÃO}

O livro Sistema Financeiro, Bancos e Financiamento da Economia: uma abordagem keynesiana tem um grande mérito em mostrar uma visão dos bancos e do sistema financeiro diferente da que é geralmente divulgada. Em especial, consegue transmitir de forma rigorosa e bem articulada a visão pós-keynesiana sobre o tema.

O livro demonstra que os bancos e o sistema bancário são de fundamental importância no que tange ao financiamento e ao crescimento econômico, evidenciando de forma clara que estas instituições não são apenas intermediadoras financeiras, mas podem contribuir efetivamente para o crescimento econômico. $\mathrm{O}$ autor também enfatiza que o sistema bancário é pró-cíclico, o que significa que, nos momento de expan-

Correspondência para Douglas Alcantara Alencar.

E-mail: dougsky@gmail.com. 
são econômica, os bancos fornecem crédito, alimentando o crescimento. Todavia, no descenso do ciclo econômico, eles aumentam a preferência pela liquidez, reduzindo o volume de crédito e aprofundando a crise. $\mathrm{O}$ autor encerra a obra com um capítulo explanatório que busca integrar a visão keynesiana e schumpeteriana.

O objetivo do livro, como destaca seu autor, é analisar a relação entre sistema financeiro, bancos e financiamento da economia, do ponto de vista da abordagem pós-keynesiana. Na Introdução, de Paula enfatiza a diferença entre a teoria pós-keynesiana e a convencional, abordando as concepções distintas sobre o papel da moeda e as instituições para o crescimento econômico e a dinâmica empresarial.

$\mathrm{Na}$ visão convencional, os bancos e as instituições financeiras são intermediários entre poupadores e investidores. Já na abordagem pós-keynesiana, o sistema financeiro tem um papel crucial para a economia - em momentos de expansão, impulsiona o crédito e, em momentos de retração econômica e incerteza, a preferência pela liquidez dos bancos aumenta, acentuando a retração do ciclo. Assim, o funcionamento do sistema financeiro, sem intervenção, é pró-cíclico. Os bancos são, nessa concepção, agentes ativos, que administram seus balanços, podendo aumentar o crédito, o que impacta no produto e emprego. O enfoque pós-keynesiano é compatível com a visão de Keynes, na qual a incerteza tem papel crucial, assim como a preferência pela liquidez.

O livro do professor Luiz Fernando de Paula retrata uma das linhas de pesquisa do autor. O primeiro capítulo tem como referência um artigo de 1999, de sua autoria, no qual ele discute a diferença entre as interpretações convencional neoclássica e pós-keynesiana. No segundo capítulo, com origem em Paula (2003), discute o comportamento dos bancos e os ciclos minskianos. O terceiro capítulo trata da relação entre sistema financeiro e crescimento econômico. Finalmente, no quarto capítulo, ele relaciona as ideias de Keynes com as de Schumpeter. Dessa forma, o livro pode ser lido na ordem que o leitor preferir; contudo, a sequência indicada no Índice permite entender com clareza a dinâmica bancária e o sistema financeiro como um todo.

\section{ESTRUTURA DO LIVRO}

O livro é dividido em quatro capítulos. No primeiro,"Dinâmica dos bancos em uma economia monetária, de Paula faz uma discussão sobre a teoria da firma bancária, sob a perspectiva convencional neoclássica e, em seguida, sob a pós-keynesiana. Os bancos, de acordo com a primeira perspectiva, são intermediários entre agentes superavitários e deficitários, funcionando apenas como uma correia de transmissão da política monetária. Dentro da visão convencional, temos duas visões distintas sobre os bancos comerciais, a "velha" e a "nova". De Paula destaca o questionamento feito por Tobin
(1987), criticando a visão que ele considerava "velha" sobre o multiplicador bancário, a qual considerava os bancos criadores "quase-técnicos" de moeda, resultante do ajustamento passivo a uma dada razão de reservas. Na visão "nova", defendida por Tobin, os bancos são limitados pelas taxas de juros e pelo custo de atrair novos empréstimos. Destarte, o constrangimento das reservas passa a ser menos importante.

Esta nova concepção do mainstream, proposta por Tobin, gerou uma série de modelos neoclássicos, sendo o principal o modelo derivado do trabalho de Santomero (1984). Na visão velha, os bancos atuam como monopólios e são, como vimos, criadores de moeda quase-técnicos. Na nova perspectiva, os bancos funcionam como gerenciadores de portfólio, neutros ao risco, otimizando os ganhos prospectivos líquidos de risco. Com base nessa abordagem elaborada por Santomero (1984), foram desenvolvidos diversos modelos neoclássicos. O autor classifica três grandes categorias de modelos e, dentro de cada uma delas, duas subcategorias. As três categorias são: i) modelos de alocação de ativo; ii) modelos de escolha de passivo; e iii) modelos completos de firma bancária.

Na perspectiva pós-keynesiana, os bancos tomam decisões em um ambiente de incerteza não probabilística, em que a moeda não é neutra e os contratos ajudam a coordenar um futuro incerto (Carvalho, 1992; Paula, 2014). Em uma economia monetária de produção, como já mencionamos, os bancos criam crédito independente de depósitos prévios, por meio da criação de moeda bancária. Nesse sentido, os bancos são como as outras firmas, tomando decisões com expectativas que afetam as condições de financiamento e, consequentemente, a produção e o emprego. As decisões de portfólio são, então, tomadas com base nas expectativas quanto aos lucros, levando em consideração a incerteza não probabilística e a preferência pela liquidez. O aumento do financiamento na economia depende das avaliações sobre as receitas esperadas futuras, ou seja, sobre a capacidade dos tomadores de empréstimos de cumprir seus compromissos.

Nesse contexto, a partir de expectativas, os bancos devem tomar uma posição mais ou menos ativa quanto aos empréstimos. O banco financia esta posição com base em um passivo cuja composição pode igualmente variar. Quando as expectativas são desapontadas, os bancos tendem a reduzir seu nível de transformação de maturidades, passando a privilegiar a liquidez.

Para Keynes (1936), a taxa de juros é a recompensa por abrir mão da liquidez, com a escolha básica ocorrendo entre dois tipos de ativos: moeda ou títulos. A demanda por moeda se dá, como se sabe, por três motivos: transação, precaução e especulação. As duas últimas relacionam-se com a incerteza em relação ao futuro. Para ele, existia um trade-off entre maiores retornos monetários e maior liquidez. 
Os bancos, na perspectiva pós-keynesiana, são movidos pelo processo de concorrência bancária e pela busca de maiores lucros, aumentando sua escala de operação, alavancagem e/ou elevando o spread bancário, por meio, entre outras, das seguintes estratégias: a) elevação do lucro líquido por unidade monetária do ativo; e b) aumento na relação entre ativo e capital próprio do banco (Minsky, 1986; Paula, 2014).

A principal conclusão do autor, nesse capítulo, é que, na perceptiva convencional, os bancos são neutros e funcionam apenas como meio de transmissão de recursos de agentes superavitários para agentes deficitários, enquanto na visão pós-keynesiana, os bancos podem criar moeda, administrando dinamicamente seus balanços e, consequentemente, aumentando ou reduzindo a liquidez do sistema econômico.

No segundo capítulo, intitulado "Comportamento dos bancos e oferta de crédito no ciclo minskiano", de Paula discute como a fragilidade financeira se relaciona com a forma de financiamento das empresas, sendo responsável pelos ciclos econômicos. $\mathrm{Na}$ fase expansiva da economia, expande-se o volume de crédito e, no descenso do ciclo, o volume de crédito é reduzido. Nesse sentido, a fragilidade financeira é um processo endógeno, gerado pela própria instabilidade econômica. Os bancos têm uma escala de liquidez, na qual diferentes graus de liquidez devem ser compensados por diferentes taxas de retorno. Assim, naquele capítulo, volta a discussão do trade-off entre liquidez e rendimento. Contudo, dentro dessa perspectiva, a questão da incerteza não probabilística é mais uma vez importante, pois o aumento da incerteza na economia aumenta a preferência pela liquidez, reduzindo o volume de crédito. Este, por sua vez, é ampliado dependendo das expectativas em relação às taxas de juros, de câmbio e às perspectivas de crescimento econômico.

Os bancos podem aumentar o volume de crédito com técnicas de administração do passivo, como, por exemplo, utilizando o gerenciamento das reservas e inovações financeiras. Nesse sentido, a moeda é endógena, já que existe a possibilidade de aumento do volume de crédito sem a necessidade de poupança ou depósitos à vista. Assim, em momentos de crise, o crédito é racionado, o que dificulta a rolagem da dívida dos agentes. Ou seja, em virtude do aumento da preferência pela liquidez, os bancos reduzem o prazo médio dos ativos, acentuando as crises.

Na sequência, o autor discute a hipótese da fragilidade financeira e a evolução do estado de expectativas dos bancos. De Paula argumenta que, nas fases de expansão da economia, as firmas tomam posições especulativas, no sentido minskiano do termo. Assim, as empresas, incluindo os bancos, reduzem as margens de segurança. O sistema financeiro tem, então, um papel importante nos ciclos econômicos, acentuando-os. $\mathrm{Na}$ fase de expansão, os bancos reduzem as margens de segurança, já que a preferência pela liquidez é diminuída pela "melhora" no estado de expectativas dos agentes e, com isso, o volume de crédito aumenta. Com a reversão das expectativas, os bancos procu- ram trocar ativos de longo prazo por ativos de curto prazo, dificultando a rolagem das dívidas dos tomadores de empréstimos e aumentando a fragilidade financeira.

No terceiro capítulo, "Financiamento, crescimento econômico e funcionalidade do sistema financeiro", o autor discute a questão do financiamento, do crescimento econômico e da funcionalidade do sistema financeiro. De Paula passa, então, a discutir essas questões do ponto de vista da teoria convencional e da visão pós-keynesiana.

A visão convencional, em especial a partir dos trabalhos de Levine (1997), passou a admitir uma relação positiva entre o financiamento e o crescimento econômico. Nessa visão, o sistema financeiro é neutro e apenas intermediário entre agentes superavitários e deficitários. Além disso, pressupõe-se concorrência perfeita, sendo funcional e fazendo uma alocação eficiente dos recursos. Dessa forma, os intermediários financeiros têm um papel crucial, ainda que basicamente mecânico, dentro dessa abordagem.

A teoria moderna da intermediação financeira é fundamentada na ideia de falhas de mercado, como, por exemplo, a informação assimétrica, que pode dificultar a intermediação. Assim, as instituições têm também como objetivo reduzir essas falhas de mercado e, consequentemente, diminuir os custos de transação. A função dos intermediários financeiros pode ser dividida, nas várias abordagens, em cinco tipos: i) velha teoria da intermediação financeira; ii) teorias a partir da assimetria de informações, que buscam controlar os problemas de risco moral e seleção adversa; iii) teorias baseadas nos custos de transação; iv) propostas de regulação para reduzir o risco de insolvência do sistema financeiro; e v) gerenciamento de risco de maturidade, inadimplência e mercado.

Depois da discussão do sistema financeiro na abordagem convencional, de Paula passa a discutir a mesma questão, do ponto de vista pós-keynesiano. Nessa visão, o setor bancário cria liquidez e a moeda é endógena ao sistema. No que tange à visão pós-keynesiana sobre sistema financeiro e crescimento, o autor retoma o debate entre Ohlin (1937a, 1937b), Robertson (1937) e Keynes (1937). Esse debate, sobre o financiamento da economia, tem os dois primeiros autores postulando a poupança como pré-condição para o financiamento da economia. Porém, para Keynes, o investimento nunca deixa de ser realizado por falta de poupança, mas sim por falta de financiamento. Pelo princípio da demanda efetiva, a poupança é ex-post, e os investimentos têm relação com o estado de expectativas dos agentes e os animal spirits. Assim, para Keynes, a oferta de fundos disponíveis não é determinada pela canalização do fluxo de poupança do período, mas pelo estoque de ativos financeiros existentes.

O processo de financiamento, como se sabe, tem duas etapas: o finance, que é o financiamento ao tomador, e o funding, que transforma o financiamento ao tomador, 
de mais "curto prazo", em um de longo prazo, fundeando o emprestador com recursos com maturação mais compatível com aquela do investimento (ou outro gasto ou aplicação) realizado pelo tomador. Keynes sugeriu um circuito que envolve financiamento-investimento-poupança-funding. Cabe ressaltar que a poupança é a contrapartida ex-post do investimento. O finance é a própria demanda por investimento planejado, que é atendido pelo setor financeiro sob a forma de moeda. Para a teoria pós-keynesiana, o sistema financeiro é funcional se permite uma expansão do crédito com o mínimo do aumento da fragilidade financeira.

Em seguida, de Paula faz uma revisão sobre os diversos tipos de sistemas financeiros pelo mundo, comparando, por exemplo, EUA, Alemanha, Brasil, entre outros. A importante conclusão a que chega é que não existe uma receita única para cada tipo de país. As experiências dos sistemas financeiros são múltiplas e diversas. Contudo, de Paula parece sugerir que, nos países retardatários do sistema capitalista, o Estado, seja regulando ou intervindo no sistema financeiro, tornou-o mais eficiente. A conclusão do capítulo é de que existe uma relação importante entre o sistema financeiro e o crescimento econômico.

Finalmente, no quarto e último capítulo o autor analisa a interação entre financiamento, sistema financeiro e a dinâmica da inovação, a partir de uma análise que busca integrar a visão neoschumpeteriana e a visão pós-keynesiana. De Paula começa esse capítulo discutindo Schumpeter (1911), que considera o processo de inovação como uma ruptura do estado estacionário, que gera duas ondas de investimento: a primeira é a própria inovação, e a segunda é uma mudança de comportamento de vários agentes, por conta da primeira. A inovação para Schumpeter é financiada via crédito, o que significa que o financiamento é um complemento monetário necessário para a inovação. Mas para Schumpeter, o crédito não depende da existência de "poupança" prévia, ou seja, a moeda igualmente é endógena ao sistema, nessa interpretação.

Keynes (1930) concorda com Schumpeter sobre a importância do processo inovativo para a mudança tecnológica. Keynes também argumenta que só é possível o empresário realizar os investimentos com a complacência do sistema bancário. Ambos os autores também discordam da dicotomia neoclássica de diferenciar o lado real e monetário da economia. Para eles, a moeda tem papel fundamental no financiamento e no funcionamento da economia. Outra semelhança é em relação ao papel do investimento. Em Keynes, pelo princípio da demanda efetiva, e, em Schumpeter, o investimento relaciona-se com a inovação, e tanto os investimentos direcionados a aquisições de bens de capital quanto aqueles dirigidos às inovações estão sujeitos à incerteza radical.

Assim, após essa primeira aproximação entre Keynes e Schumpeter, de Paula discute a questão da seleção da inovação, tema caro aos neoschumpeterianos. Argu- menta, uma vez mais, que as decisões de investimento, assim como as de inovar, encontram-se sob a incerteza não probabilística, vale dizer, em um mundo não ergódico. De Paula relaciona diferentes tipos de inovação a diferentes graus de incerteza. As inovações radicais, que necessitam de novos conhecimentos, estão associadas à incerteza radical, ao passo que as inovações incrementais estão associadas a um grau menor de incerteza. Nesse sentido, o investimento em pesquisa e desenvolvimento $(\mathrm{P} \& \mathrm{D})$ está mais associado à incerteza radical, pois se trata de um ativo intangível muitas vezes com menor conhecimento quanto ao quê, quando e como será conseguido, e os resultados possíveis de tudo isso. Assim, o investimento em P\&D tem custos de financiamento frequentemente maiores (por exemplo, em termos de taxas de retorno, pelo menos as mais previsíveis) do que em outras formas de investimento, como o capital fixo. Logo, as firmas intensivas em $P \& D$ devem ser mais inclinadas a utilizarem recursos internos para seu financiamento, quando comparadas a outras firmas e/ou outros financiamentos.

O autor, na penúltima seção do capítulo, retoma a discussão sobre a funcionalidade do sistema financeiro de um país, relacionando-a à ideia neoschumpeteriana do sistema nacional de inovação (SNI). Na sua visão, o sistema financeiro, assim como outros aspectos, como formação de conhecimento, universidades etc., fazem parte do SNI. De Paula (2014) segue as conclusões de um importante autor brasileiro que discute a questão do SNI (Albuquerque, 1996), para o qual não existe uma receita pré-definida para a funcionalidade do sistema financeiro com relação ao SNI e, em diferentes países, o sistema bancário responde de forma diferente quanto à sua maior ou menor integração ao sistema de inovação.

\section{REFERÊNCIAS}

ALBUQUERQUE, E. M . Estruturas Financeiras, Funcionalidade e Sistemas Nacionais de Inovação. Nova Economia, Belo Horizonte, v. 6, n.2, p. 113-138, 1996.

CARVALHO, F. C. Mr. Keynes and the post keynesians. Cheltenham, UK: Edward Elgar, 1992.

KEYNES, J. M. A treatise on money, two volumes complete in one. Mansfield Centre: Martino Publishing, 1930/2011.

KEYNES, J. M. A teoria geral do emprego, do juro e da moeda. São Paulo: Editora Nova Cultural, 1936.

LEVINE, R. Financial development and economic growth: views and agenda. Journal of Economic Literature, n. 35, 1997.

MINSKY, H. Stabilizing an unstable economy. New Haven: Vale University Press, 1986. 
OHLIN, B. Some notes on the Stokholm theory of saving and investment. Economic Journal, v. 47 , n. 185 , p. 52-69, 1937a.

OHLIN, B. Alternatives theories of the rate of interest, three rejoinders. Economic Journal, v. 47, n. 187, p. 423-427, 1937 b.

PAULA, L. F. R. Dinâmica da firma bancária: uma abordagem não-convencional. Revista Brasileira de Economia, Rio de Janeiro, v. 53, n.3, p. 323-356, 1999.

PAULA, L. F. R.; ALVES JR, A. J. Comportamento dos bancos, percepção de risco e margem de segurança no ciclo minskiano. Análise Econômica, Porto Alegre, v. 21, n. 39, p. 137-162, 2003.

PAULA, L. F. R. Financiamento, crescimento econômico e funcionalidade do sistema financeiro: uma abordagem pós-keynesiana. Estudos Econômicos, v. 43, p. 363-396, 2013.

PAULA, L. F. R. Sistema financeiro, bancos e financiamento da economia. 1. ed. Rio de Janeiro: Campus Elsevier, 2014.

ROBERTSON, D. Alternatives theories of the rate of interest, three rejoinders. Economic Journal, v. 47, n. 187, p. 428-436, 1937.

SANTOMERO, A. M. Modeling the banking firm. Journal of Money, Credit, and Banking, v.16, n. 4, p. 576-602, nov. 1984 .

SCHUMPETER, J. A. The theory of economic development. New Brunswick/London: Transaction Publishers, 1911.

TOBIN, J. The commercial banks as creators of "money". In: TOBIN, J. Essays in Economics. Cambridge, MA: MIT Press, 1987. v. 1. 